\title{
AULAS ON-LINE DE INSTRUMENTOS MUSICAIS: NOVO PARADIGMA EM TEMPOS DE PANDEMIA
}

\section{MUSICAL INSTRUMENTS ONLINE LESSONS: NEW PARADIGM IN PANDEMIC TIMES}

\author{
Daniel Marcondes Gohn \\ Universidade Federal de São Carlos \\ dgohn@uol.com.br
}

\section{Resumo}

Este texto lança um olhar sobre o cenário da pandemia de Covid- 19 no início de 2020, período que ocasionou profundas transformações na sociedade e reconfigurações no campo da educação musical. É apontada uma diferenciação entre ações de ensino remoto realizadas de forma emergencial e a educação a distância (EAD), quando aplicada com planejamento, pedagogias específicas e condições tecnológicas favoráveis. Na Universidade Federal de São Carlos (UFSCar), instituição que serve como base para as reflexões aqui apresentadas, há um processo bem elaborado e estruturado na Licenciatura em Educação Musical, oferecido na modalidade a distância em parceria com o projeto Universidade Aberta do Brasil (UAB). Em contrapartida, diversas instâncias da instituição discutiram ações emergenciais para lidar com a necessidade de distanciamento social, utilizando recursos tecnológicos como apoio. A partir do contexto pandêmico, emergiram também debates em vários âmbitos na internet, promovendo discussões no sentido de lapidar aulas on-line de instrumentos musicais. Percebe-se nesse contexto o surgimento de um novo paradigma, no qual a comunicação síncrona, por meio de softwares de videoconferência, poderá ter um papel mais relevante do que tinha em modelos de trabalho anteriores, como no exemplo do curso UAB. O presente trabalho oferece elementos específicos para aulas on-line de bateria, buscando a superação de adversidades não somente no período de enfrentamento do Covid-19, mas também para desafios que permanecerão no pós-pandemia.

Palavras-chave: educação a distância; aulas on-line; pandemia; Covid-19; bateria. 


\begin{abstract}
This paper sheds some light on the scenario brought by the Covid-19 pandemic in the beginning of 2020, a period that led to deep transformations in society and reconfigurations in the music education field. The article states a differentiation between actions of distance teaching that were took as emergency solutions and distance education, when applied with actual planning, specific pedagogies, and favorable technological conditions. At the Federal University of São Carlos (UFSCar), the institution that grounds the thoughts presented herein, there is a well-structured process taking place within the Music Education program offered completely in distance education mode, in a partnership with the project Brazilian Open University (UAB). On the other hand, several discussions were held in order to deal with the need for social distance, having the support of technological means of communication. With the pandemic, debates emerged also throughout the internet, promoting the exchange of ideas to improve online lessons of musical instruments. This context results in a new paradigm, in which synchronous communication, through videoconferencing software, might have a stronger role than before, considering settings such as the UAB course previously mentioned. This article offers specific elements for online drum set lessons, in a search to overcome adversities not only of the Covid-19 period, but also challenges that may remain after the pandemic.
\end{abstract}

Keywords: distance education; online lessons; pandemic; Covid-19; drum set.

\title{
Contexto geral
}

O cenário da pandemia de Covid- 19 no início de 2020 apresentou enormes desafios para a educação, em todo o mundo. Com a necessidade de distanciamento social, recomendado pela Organização Mundial da Saúde e amplamente divulgada nos meios de comunicação, muitos professores foram colocados frente à demanda de dar continuidade a suas aulas à distância, em alguns casos sem ter nenhuma experiência anterior nessa modalidade de ensino. Dessa forma, não houve o devido tempo para planejamento, preparação de materiais, para o aprendizado sobre as tecnologias envolvidas e principalmente sobre as pedagogias inerentes ao trabalho à distância. Na área da música,

\section{3}

REV. TULHA, RIBEIRÃO PRETO, v. 6, n. 2, pp. 152-171, jul.-dez. 2020 
- desafio tornou-se exacerbado pelas diversas especificidades das disciplinas, particularmente naquelas em que estão envolvidos aspectos práticos com instrumentos musicais.

Desde o final do século XX, quando a acentuada disseminação da internet comercial facilitou novos meios para a educação a distância (EAD), os recursos tecnológicos usados para aulas de instrumentos musicais nessa modalidade têm sido investigados ( $C O H N, 2003$ e 2011 ). Com o avanço de tais pesquisas, constatou-se que a possibilidade de transmissão de áudio e vídeo síncronos, em tempo real, sem qualquer compressão de áudio ou atrasos na relação entre imagem e som, já existia na prática, mas com demandas tecnológicas ainda muito distantes da realidade da maioria dos professores de música (COHN, 2015). A utilização de um software como o LOLA (Low Latency), por exemplo, além de uma conexão com largura de banda extremamente alta, viável somente em redes eletrônicas como a Internet2 (wwwinternet2.edu), também demanda o uso de equipamentos de hardware específicos (DAVIES, 2015). Despontando no horizonte futuro, quando a tecnologia da Internet2 estiver amplamente disponivel, teremos a veiculação de "áudio e vídeo em tempo real com uma qualidade técnica que nos dias atuais somente pode ser obtida por meio de tecnologias gravadas" (MOORE; KEARSLE, 2007, p. 96).

que se observou no decorrer do século XXI, então, foi o crescente uso dos recursos de videoconferência que estavam disponiveis gratuitamente (ou a baixo custo), ou seja, as tecnologias VolP (Voice over Internet Protocol), em softwares como Skype e FaceTime (COHN, 2013) e outros mais recentes como Coogle Meet e Zoom. Embora pesquisas apontem problemas com esses recursos, incluindo interrupções na comunicação, baixa qualidade de áudio e vídeo, e inconsistências e descompassos na conectividade (ARCHIBALD et al., 2019), os serviços têm sido aperfeiçoados e complementados com novas ferramentas, à exemplo da capacidade de gravar e armazenar o registro das sessões realizadas.

Entretanto, esses softwares foram desenvolvidos para comunicações da voz falada, não para o trabalho com música. Há uma forte compressão dos dados digitais, o que resulta em um "achatamento" das frequências na transmissão (COHN, 2015), impedindo uma qualidade suficiente para a percepção de todas as nuances musicais. A figura I ilustra como a tecnologia VoIP (Low-Bandwidth Videoteleconferece)

\section{4}

REV. TULHA, RIBEIRÃO PRETO, v. 6, n. 2, pp. 152-171, jul.-dez. 2020 
se aproxima do espectro de frequências da voz falada (Speech), ao passo que seria necessária uma amplitude maior, de softwares sem compressão de dados como o LOLA (High-Bandwidth Videoteleconference), para total adequação ao trabalho com música, por exemplo, com os instrumentos de cordas de uma orquestra (Orchestral Strings).

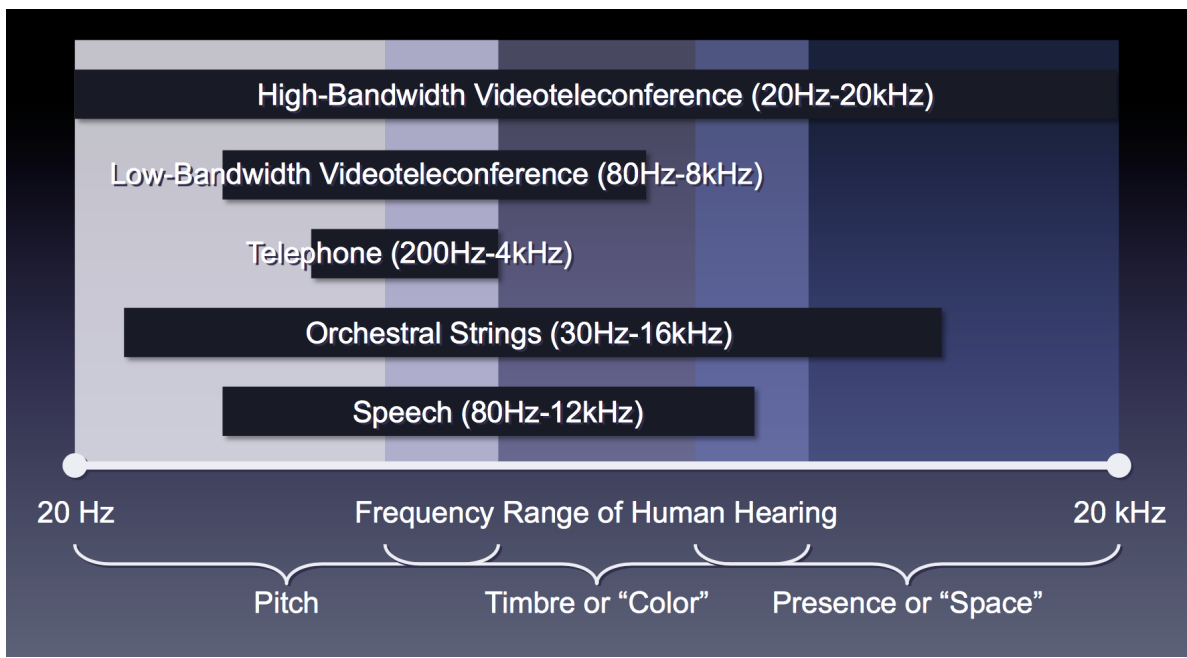

Figura 1: tabela de frequências (SHEPARD, 2012)

Dentro desse contexto, na Universidade Federal de São Carlos (UFSCar), desde 2007, foi percorrida uma trajetória com a Licenciatura em Educação Musical, um curso oferecido na modalidade a distância em parceria com o projeto UAB (Universidade Aberta do Brasil). Não houve uma institucionalização desse projeto e o curso foi descontinuado, após sucessivos cortes das verbas vindas do governo federal, pois as limitações do corpo docente do Departamento de Comunicações e Artes (DAC/NFSCar) tornavam imprescindivel a participação de professores externos. A última oferta de vestibular ocorreu em 2013 e, após o ingresso de 1073 alunos, a Licenciatura em Educação Musical a distância permanece em funcionamento somente até o primeiro semestre de 2022, quando qualquer aluno remanescente será jubilado. $\bigcirc$ formato adotado para esse curso foi assíncrono, com uso do ambiente virtual de aprendizagem (AVA) Moodle. Portanto, nas disciplinas específicas de instrumentos musicais, o uso de vídeos pré-gravados foi o meio pelo qual as aulas foram realizadas, com todas as vantagens e desvantagens 
desse modelo, sendo a comunicação síncrona usada somente em momentos pontuais (COHN, 2011 ).

\section{Novo paradigma}

Surpreendidos pela pandemia de Covid-19, a realidade de todos os professores de música (fosse lecionando em conservatórios, escolas livres, instituições superiores ou atuando de forma privada) foi direcionada para aulas on-line, impelindo-os a escolhas entre duas opções iniciais: atividades assíncronas, com a demanda da preparação de ambientes virtuais e seus conteúdos didáticos; e atividades síncronas, para as quais a tecnologia VolP se tornou um padrão. No interesse ou na obrigação de manter suas atividades, muitos professores ligaram seus laptops e começaram a lecionar via internet. No ensino superior público, somente 6 das 69 universidades federais adotaram o ensino a distância no primeiro semestre de 2020, enquanto 59 suspenderam as aulas e as demais mantiveram atividades parcialmente. A principal preocupação em relação à EAD foi a falta de acesso a recursos tecnológicos por grande parte dos alunos, que muitas vezes não tinham nenhuma forma de acesso à internet (PAIXÃO, 2020).

A UFSCar foi uma das instituições que manteve atividades parciais: nos cursos de música, a licenciatura a distância do projeto UAB continuou com o semestre e o curso presencial suspendeu as aulas. Deu-se início a uma sequência de reuniões virtuais, entre as diversas instâncias da universidade, para definir como seria a retomada das atividades. Os professores foram incentivados a se manifestarem sobre as possibilidades de suas disciplinas, preparando o terreno do que seria realizado posteriormente. Contudo, ao contrário do que ocorreu na formulação do curso no âmbito do projeto $U A B$, quando havia equipes para a produção de materiais impressos e audiovisuais, assim como para a criação e a manutenção dos ambientes virtuais, o apoio para desenvolver alternativas assíncronas seria limitado. Ainda que a UFSCar tenha ampla experiência na EAD e conte com a Secretaria Geral de Educação a Distância (SEaD), órgão responsável por dar suporte à universidade nesse campo, a demanda simultânea de todos os professores da universidade seria indirimivel. 
A falta de apoio também ocorreu em outras instituições, em diversos niveis de ensino, e foi evidenciada em manifestações de professores nas redes sociais. Em relação à exigência repentina de atuar em EAD, surgiram muitos relatos sobre dificuldades no uso de tecnologias e pedagogias que desconheciam, ao mesmo tempo em que lidavam com as dificuldades extras causadas pelos riscos do Covid- 19 (BORCES, 2020). É importante ressaltar que muitos professores, além de manter suas aulas on-line, deveriam orientar a educação de seus filhos, que não estavam frequentando as escolas, e também cuidar da manutenção da casa sem nenhum auxilio externo, para que o isolamento social fosse respeitado. Ficou evidente a distinção entre a educação a distância, planejada e estruturada, e o ensino remoto emergencial, resultado de adversidades que atingiam a sociedade como um todo.

Há uma enorme diferença entre a oportunidade de produzir uma disciplina no formato EAD, com meses de antecedência, fazendo ajustes pontuais depois de cada oferta, e o infortúnio repentino de transferir diversas disciplinas presenciais para esse formato, independentemente das experiências anteriores dos professores nessa área. É inviável propor que os conteúdos de todo um semestre sejam subitamente convertidos em arquivos digitais e organizados em um ambiente virtual. Da mesma maneira, professores de música fora de instituições formais, que atuavam exclusivamente na esfera presencial, não tiveram a comodidade de desenvolver suas metodologias de EAD com tranquilidade. Todos foram forçados a atuar em esquema de ensino remoto emergencial, em geral priorizando o formato síncrono e tendo como base softwares projetados para a voz falada, apesar das deficiências já apontadas. Um novo quadro se desenhava, no qual professores e alunos teriam que se adaptar aos estudos mediados por meios tecnológicos, em tempo real.

Não houve grande mudança nas tecnologias de videoconferência, em relação à qualidade de transmissão de áudio e vídeo, no início de 2020. Ainda assim, ocasionado pela pandemia, há um novo paradigma em instauração, no qual o contato entre professores e alunos de música se dará com mais frequência por meio de tecnologias como Skype e Zoom, a despeito dos problemas que isso acarreta. Isso confere uma maior relevância a essa forma de comunicação do que existia em modelos de trabalho anteriores, em cursos de EAD com base assíncrona. No passado recente, em muitas instituições havia essa tendência assíncrona, com uso de vídeos pré-gravados, para assegurar um controle de qualidade nos conteúdos transmitidos. Essa foi a norma estabelecida

\section{7}

REV. TULHA, RIBEIRÃO PRETO, v. 6, n. 2, pp. 152-171, jul.-dez. 2020 
pela UFSCar para o projeto UAB, evitando falhas nas comunicações, especialmente em disciplinas envolvendo a prática musical. Pairava no ar a expectativa futura de que tecnologias de videoconferências de alta qualidade, sem nenhuma compressão de dados, a exemplo do LOLA, ficassem acessíveis para a EAD de música. No novo paradigma, a situação emergencial provocada pela pandemia colocou o modelo síncrono em evidência imediata, sem chances de espera por mais avanços tecnológicos.

Consequentemente, a emergência causou uma urgência na busca por respostas, e com isso as instituições que optaram pelo ensino remoto tiveram que relevar muitas questões sociais e territoriais. Nem todos os professores e alunos vivem em regiões com internet de boa velocidade e têm acesso aos equipamentos necessários, o que provoca desafios tecnológicos e socioeconômicos. Os equacionamentos de caráter universal não captam singularidades e são apresentados como solução somente para aqueles que têm condições de avançar em seus estudos. Dito isso, na impossibilidade de um encaminhamento ideal, no qual haveria a produção de conteúdos com antecedencia, a opção de trabalho em tempo real, por meio de videoconferências, representa um "caminho do meio". Não ocorre um processo com todas as potencialidades da EAD, mas criam-se alternativas para o enfrentamento da calamidade pública.

\section{Aulas de bateria}

Para lidar com o cenário pandêmico, deu-se início a pesquisas para responder ao seguinte questionamento: como poderiam ser realizadas de forma on-line as aulas de bateria do curso presencial da UFSCar? Ficou inequivoca a importância dessa questão não somente para a retomada das atividades do curso, mas também para sua continuidade no pós-pandemia. A portaria 2.117, de 6 de dezembro de 2019, já ampliava para 40\% o limite da carga horária de EAD nos cursos presenciais das Instituições Federais de Educação Superior (BRASIL, 2019). Com a sombra de um vírus ameaçando retornar em ondas sucessivas, o repensar sobre o uso das ferramentas tecnológicas para situações de separação geográfica impostas tornava-se necessário.

Em aulas de instrumentos musicais on-line, além de pedagogias apropriadas, é preciso também dar atenção à qualidade das 
comunicações, para minimizar problemas e garantir o aprendizado planejado. Estudos sobre aulas síncronas com uso da tecnologia VolP mencionaram problemas de atrasos na transmissão de som e imagem (delay), mudanças nas dinâmicas interpessoais, limitações visuais, limitações de movimentos pelo uso de fones, controles de volumes, entre outras questões (BOUMAN, 2014). Para contornar essas situações, mesmo que parcialmente, foi colocado como objetivo um aprimoramento das videoconferências para as aulas de bateria. Compreendia-se que as especificidades do instrumento deveriam ser consideradas.

As particularidades de cada instrumento musical são determinantes no resultado de aulas on-line, especialmente no que tange a atividades síncronas. Frente as mesmas condições tecnológicas, a intensidade e a gama de frequências produzidas por diferentes instrumentos interferem na transmissão de dados, possivelmente criando demandas de equipamentos adicionais. No caso da bateria, com as características de seu conjunto de elementos percussivos, há dois fatores essenciais: a forte intensidade em potencial e as diferentes qualidades sonoras. Trata-se de um instrumento complexo, que une a caixa, oriunda dos campos de batalha da Europa; os tom-tons, vindos da China; o bumbo, da Ásia Ocidental; e os pratos, da Turquia (DEAN, 2012).

$\bigcirc$ nivel de pressão sonora da bateria pode ultrapassar $110 \mathrm{~dB}$, dependendo do ritmo e do BPM (batidas por minuto), abrangendo um espectro de frequências que ultrapassa os limites entre 60 hertz a 5000 hertz (GRANZOTTO; RUCCERI, 2010). Logo, sem o uso de microfones apropriados, uma aula on-line de bateria é suscetível a distorções na transmissão, por ter uma entrada de sinal superior às capacidades do sistema. Também ocorre a compressão anteriormente mencionada, restringindo as nuanças que são percebidas e dificultando o processo de ensino e aprendizagem. Por exemplo, pequenas variações nas formas de tocar os pratos podem ter importância significativa na execução de determinados ritmos, como ocorre nos ritmos brasileiros (COHN, D., 2020).

Na situação mais simples, isso é, professor e aluno ligam seus aparelhos (desktops, laptops, tablets ou celulares), se conectam à internet e realizam a aula via Skype ou software similar, existem limitações tanto na transmissão de dados como na captação do áudio. Afinal, os pequenos microfones desses aparelhos também foram projetados para a voz falada. As limitações podem ser mitigadas se há microfones externos, conectados ao computador por meio de uma interface de áudio, 
proporcionando níveis adequados no sinal de entrada. Dessa forma, pode-se escolher microfones específicos para as diferentes qualidades sonoras da bateria, como os graves do bumbo e os agudos dos pratos. Elemento adicional pode ser uma mesa de som, com a qual é feito o controle da equalização de cada microfone, resultando em um sinal de áudio único que entra no sistema, de forma equilibrada, evitando qualquer saturação.

Durante a pandemia, houve ampla circulação de informações na internet entre professores de música. Muitos músicos, em especial bateristas, compartilharam experiências para lapidar a qualidade de suas aulas on-line. Em conferências virtuais organizadas pelo setor educacional da empresa de pratos Sabian (www.sabianed.com), Jim Toscano ofereceu diversos modelos de trabalho com áudio e vídeo nos softwares de videoconferência. Certas orientações eram simples, como os ajustes para "reduzir o ruido de fundo", presente nas configurações avançadas do Zoom, e outras eram mais complexas, como a indicação dos softwares complementares Ladiocast e Soundflower. Percebe-se que os aprendizados mais simples poderiam acontecer mediante tentativa e erro, naturalmente no uso contínuo dos softwares de videoconferência, mas que os aprendizados complexos surgem somente a partir do contato com o conhecimento daqueles com maior experiência tecnológica.

Os aplicativos Ladiocast e Soundflower são gratuitos e tornam possivel o roteamento de vários elementos (som da bateria, microfone para a voz, aparelhos externos, áudio de websites ou de programas do próprio computador) dentro da máquina, para chegarem como sinal único na plataforma de videoconferência utilizada. Ambos são exclusivos para o sistema operacional Mac, mas existem alternativas similares para a plataforma Windows. $\bigcirc$ Ladiocast serve como uma espécie de "mesa de som" interna no computador, enquanto o Soundflower é uma extensão do sistema de áudio que permite a programas acessar a placa de som. Como resultado preliminar da pesquisa realizada, foi escolhido para as aulas de bateria da UFSCar o esquema representado na figura 2, indicado por Toscano (2020) como cenário 2.1, no qual uma câmera é acoplada ao computador e uma interface de áudio passa pelos softwares Ladiocast e Soundflower, para depois chegar ao programa Skype, Zoom ou FaceTime. 


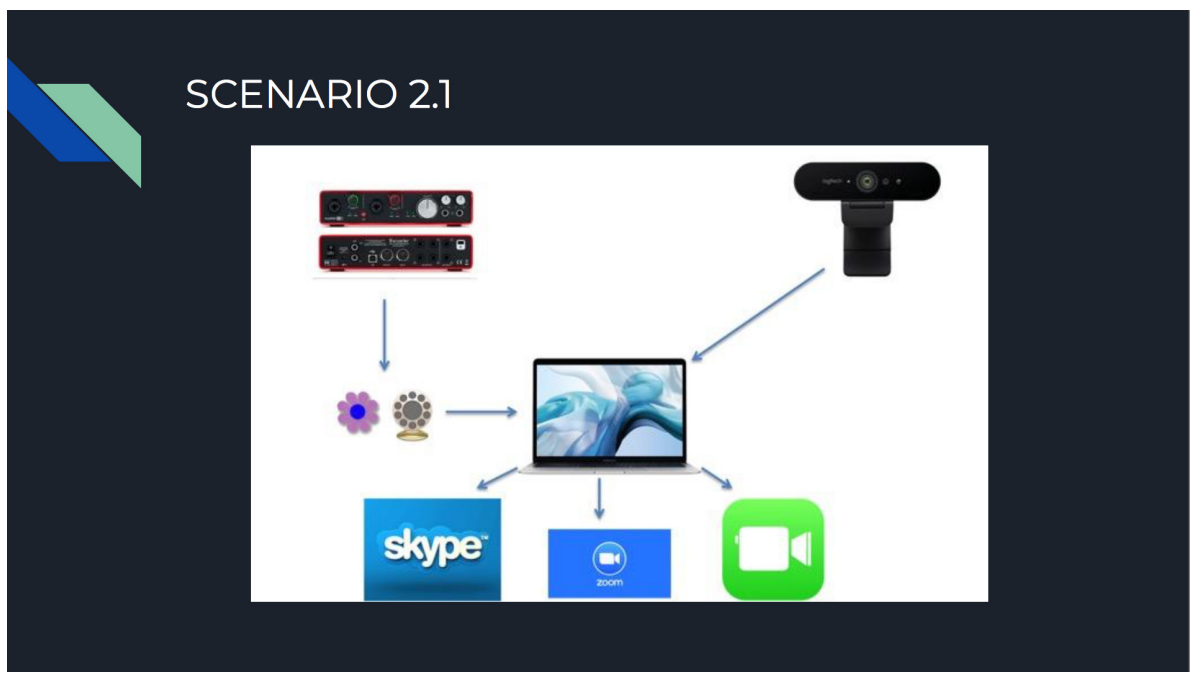

Figura 2: Esquema escolhido para aulas na UFSCar (TOSCANO, 2020)

Existem situações intermediárias entre os extremos tecnológicos apresentados (microfone do próprio celular, laptop, etc. versus diversos microfones específicos para cada peça da bateria). Por exemplo, podese utilizar um único microfone externo de qualidade superior, por meio da placa de áudio, para melhorar a captação geral de toda a bateria. Nessa situação, ainda que a captação sonora seja aprimorada, o controle de intensidades e frequências permanece limitado, ficando o resultado condicionado às características do microfone escolhido. Suas capacidades irão valorizar determinados elementos da bateria, em detrimento de outros. Certamente, existem microfones com ampla resposta de frequência, mas a captação a partir de um único ponto impede ajustes específicos para cada componente do instrumento.

Trabalhar com as propriedades acústicas da bateria envolve uma série de fatores complicadores, e independentemente dos equipamentos disponíveis, o local para a aula deve ser apropriado. A reverberação no ambiente deve ser considerada, evitando o som "embolado" por reflexões excessivas, e deve haver isolamento acústico em relação ao espaço exterior, para possibilitar a prática com o instrumento sem limitações quanto à intensidade sonora. Podem ocorrer complicações com vizinhos, por exemplo, ao tocar no período da noite, caso o local não seja adequado. Essa adversidade é ainda mais acentuada para 
aqueles que residem em apartamentos $e$, com as restrições impostas pela pandemia, ficaram impedidos de ir a estúdios profissionais ou a salas preparadas para a performance musical.

\section{Equipamentos para aulas on-line}

Durante a pandemia, o contexto para as aulas on-line de bateria da UFSCar era o seguinte: o professor residindo em apartamento, estavam disponíveis uma interface de áudio de dois canais e um microfone, conectados a um laptop com boa conexão à internet. Como alternativa para lidar com os problemas específicos da bateria que foram colocados, foi feita então uma opção tecnológica: a bateria eletrônica. $\bigcirc$ modelo TD-27 (figura 3), produzido pela empresa Roland, foi escolhido por ter mais de 700 timbres que podem ser configurados de diversas maneiras, e principalmente por ter a caixa e o prato de condução muito próximos da realidade dos equivalentes acústicos, com tamanhos de 14 e 18 polegadas, respectivamente. Muitas baterias eletrônicas têm peças de tamanhos bem menores e não possuem a sensibilidade e as variações de timbres que o modelo citado apresenta.

A história das baterias eletrônicas teve início em 1971, quando a banda inglesa The Moody Blues utilizou um protótipo na gravação do disco Every Good Boy Deserves Favour (DEAN, 2012). É fundamental diferenciar "percussão eletrônica", termo mais genérico que faz referência a equipamentos diversos que vêm surgindo desde a década de 1930 (BRETT, 2016), do que estamos chamando de "bateria eletrônica". $\bigcirc$ desenvolvimento da percussão eletrônica deu origem a diversas máquinas que produziam ritmos programáveis, mas "bateria eletrônica" aqui faz referência aos instrumentos com superfícies para tocar que simulam um instrumento acústico, disparando sons eletronicamente por meio de sensores que captam estímulos e os transformam em sinais elétricos. A qualidade dessa simulação foi aperfeiçoada ao longo das décadas, mas "não importa quão sensiveis são as superfícies de disparo e as nuanças de suas amostragens, a emulação da sensação e do som da percussão acústica permanece imperfeita" (BRETT, 2016, p. 89). A despeito dessas imperfeições, houve considerável avanço com as "peles de tela" (mesh heads), material sintético que substituiu as superfícies de borracha comumente utilizadas. Também com os pratos de borracha houve uma aproximação da simulação eletrônica com as complexas 
sonoridades e sensações produzidas pelas ligas metálicas dos pratos acústicos (DEAN, 2012).

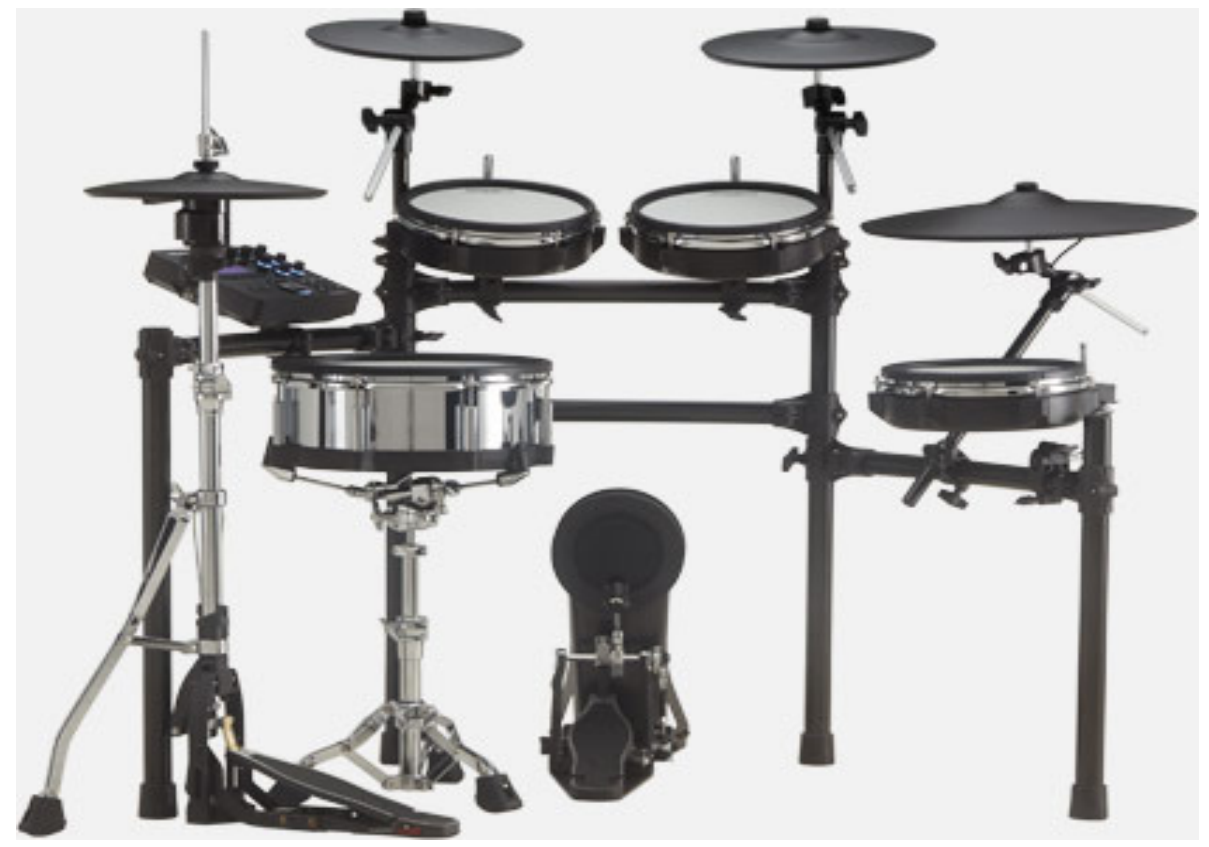

Figura 3: Bateria eletrônica TD-27, com "peles de tela" (https://www.roland.com/br/products/td-27kv)

Tendo em vista a finalidade de lecionar on-line, em oposição a qualquer pretensão artística ou comercial, a opção pela bateria eletrônica é justificada pelo controle total sobre o som transmitido. Cada peça do instrumento pode ser ajustada separadamente, seja em relação à intensidade, afinação, timbre ou duração. Pode-se escolher sonoridades específicas para cada situação, de acordo com o gênero musical ou o tópico em discussão. Por exemplo, geralmente o som de uma bateria de jazz tem afinações mais altas e pratos de sonoridades descritas como mais "escuras", diferentemente dos sons que são comuns para rock ou funk. Como o sinal da bateria entra diretamente na interface de áudio, o microfone para a voz do professor transmite a voz sem "competir" com o som do instrumento. Portanto, é possível tocar e 
falar ao mesmo tempo, algo que se mostra bastante difícil com o uso da bateria acústica.

Além disso, não existe nenhuma demanda especial para o local da aula, pois o uso de fones de ouvidos possibilita que a produção sonora seja mínima, causada apenas pelo impacto das baquetas nas superfícies de disparo. Ficam assim resolvidas as restrições nos apartamentos e limitações de horários, pois mesmo durante a noite pode-se tocar sem incômodo a moradores vizinhos. Esse último detalhe torna-se importante para que a organização das aulas possa respeitar eventuais dificuldades na agenda dos alunos. Não obstante as diferenças em relação aos instrumentos acústicos, a experiência com baterias eletrônicas modernas, com as mais recentes tecnologias, torna evidente que seu uso não traz nenhum prejuízo no processo de ensino e aprendizagem. $\bigcirc$ aspecto negativo que emerge são os custos do equipamento, que podem ser bastante elevados.

professor pode criar condições favoráveis para a comunicação on-line, mas cada aluno trará circunstâncias diferentes, subordinadas aos seus equipamentos e local disponivel para a aula. $\bigcirc$ aluno possui um laptop ou um celular? Qual a velocidade da sua conexão à internet? Possui um bom fone de ouvido? Microfone externo ou do laptop? Sendo uma bateria acústica, há algum tratamento acústico no espaço? Dificilmente todas essas perguntas terão as mesmas respostas em um grupo de alunos, gerando diferentes obstáculos em cada aula. Se, por um lado, a comunicação a distância apresenta tais variáveis, por outro há uma constante positiva: o professor observa a performance do aluno em seu próprio instrumento. Na educação presencial, quando o aluno se desloca até o local da aula e demonstra o que estudou, isso ocorre no instrumento do professor ou da instituição de ensino. A melhor forma de auxiliar o aluno é observá-lo nas condições em que pratica todos os dias, com a bateria que utiliza em suas apresentações e produções musicais.

Primordial é assegurar que os alunos tenham os meios para participar da aula, com um aparelho eletrônico conectado à internet e banda larga suficiente para viabilizar as videoconferências. Um formulário eletrônico foi usado para obter informações nesse sentido junto aos alunos de bateria da UFSCar, conforme detalhes apresentados a seguir. Diante das incertezas econômicas geradas pelo Covid-19, era antecipado que os alunos não teriam condições de adquirir quaisquer 
equipamentos para realizar atividades a distância, por mais que a perspectiva de atividades on-line no pós-pandemia fosse iminente. Para o professor, houve a necessidade de consideráveis investimentos financeiros, o que foi tido como crucial e urgente, dado o futuro próximo em que muitas atividades teriam que ser transferidas para o formato a distância. No caso da bateria, o uso do instrumento eletrônico contorna adversidades que surgem com o equivalente acústico; no caso dos demais instrumentos musicais, devem ser considerados os equipamentos apropriados para a captação específica das sonoridades em questão.

\section{A visão dos alunos}

grupo de alunos de bateria no primeiro semestre de 2020 contava com treze indivíduos, que estavam divididos em quatro turmas. Por meio de um formulário on-line, foram analisados o acesso a tecnologias e as expectativas desse coletivo. Embora todos tivessem celulares e computadores e condições descritas como "boa" ou "ótima" para realizar videoconferências, sobre as aulas on-line de bateria a maioria indicou que "não achava uma boa ideia", mas que seria válido por não haver outra alternativa no decorrer das restrições geradas pelo Covid-19. De certa forma essas respostas revelavam um desprestígio em relação à EAD, ainda que não tivessem sido dados detalhes sobre os formatos a serem adotados, nem mesmo se haveriam atividades síncronas ou assíncronas. Logo, a despeito da realidade em que esses alunos fazem uso constante de aparelhos tecnológicos para buscar informações na rede, constata-se o resquício de um certo preconceito contra a EAD, algo que também percebe-se há tempos em "educadores que não conseguiram soltar os laços nostálgicos com a forma pela qual eles mesmos aprenderam" (LITTO, 2010, P. 4 I).

Essas respostas devem ser contextualizadas na perplexidade de toda a sociedade frente à pandemia, causadora de uma vasta gama de dificuldades familiares e problemas psicológicos. Há de ser considerado ainda que esses alunos se matricularam em um curso presencial e jamais se comprometeram a atividades totalmente a distância. Mas, conforme o preceito básico da Teoria da Distância Transacional de Michael Moore, "a distância é um fenômeno pedagógico, e não simplesmente uma questão de distância geográfica" (MOORE; KEARSLEY, 2007, p. 239), ou seja, pode existir distanciamento entre aluno e professor mesmo nas aulas presenciais. $\bigcirc$ desafio é promover uma sensação de

\section{5}

REV. TULHA, RIBEIRÃO PRETO, v. 6, n. 2, pp. 152-171, jul.-dez. 2020 
proximidade em aulas on-line para superar preconceitos contra a EAD, potencializados pela conjuntura do coronavírus. Entretanto, o processo para atingir esse objetivo só seria iniciado com as aulas, e no momento inicial o foco estava nas condições dos alunos para participarem efetivamente das atividades.

Nesse sentido, foi significativo que absolutamente nenhum deles tivesse acesso a uma impressora em casa. Quando o professor envia o arquivo de uma partitura e considera que o conteúdo está materializado ao lado do aluno, poderá estar cometendo um erro. Muitas vezes, situações não previstas podem surgir se não há como produzir cópias físicas em papel, pois interpretar partituras a partir do celular não é adequado, e se o computador está sendo usado para uma videoconferência a tela maior não fica disponível. Pode-se até abrir a partitura, mas perde-se o contato visual com o professor. Outra questão fundamental, mais básica, é que nem todos tinham acesso a uma bateria em casa, pois normalmente se deslocavam até outro local (igreja, universidade, etc.) para estudar. Essa adversidade não impede por completo que tarefas sejam realizadas, mas certamente direcionam o planejamento das atividades. Todos que indicaram não ter a bateria, em contrapartida afirmaram ter disponíveis outros instrumentos de percussão, como pandeiro e cajon, o que abre o leque de possibilidades.

Finalmente, foi investigado como estava a agenda dos alunos durante a pandemia. Muitos retornaram para suas cidades de origem e tiveram que se adaptar a realidades desfavoráveis aos estudos. A dúvida, além do aspecto psicológico envolvido, era sobre a disponibilidade para se dedicarem à prática musical. A partir de relatos de colegas, parentes e conhecidos percebia-se que a rotina das pessoas durante esse período tão atípico podia ser muito variada, abrangendo desde aqueles com tempo para iniciar novas empreitadas, por vezes com sensações de tédio pela falta de compromissos, até aqueles que tiveram que assumir tarefas domiciliares diversas (limpar a casa, preparar alimentos, cuidar de parentes, auxiliar o estudo dos filhos, etc.) e estavam estressados com suas atribulações e contratempos. No caso dos alunos pesquisados, todos indicaram que tinham muitas tarefas em alguns dias, mas que poderiam organizar suas agendas para se dedicarem adequadamente aos estudos.

Tendo em vista que existia um outro curso de música na UFSCar, oferecido na modalidade à distância em parceria com a UAB, e isso 
serviu como referência de EAD para esses alunos do presencial, é compreensivel que suas expectativas sejam de uma "transferência" para os moldes daquele curso, o que dificilmente ocorreria. Conforme já observado, não havia a mesma estrutura de recursos humanos e tecnológicos, o que inviabiliza a produção de ambientes virtuais no mesmo esquema, mas em compensação, a quantidade de alunos no curso presencial é bem menor, possibilitando maior atenção individual e facilitando o gerenciamento de atividades síncronas. As perspectivas futuras para o pós-pandemia certamente irão transformar a visão geral sobre a $E A D$, com muitas adaptações a aulas on-line e com a intensificação de modelos híbridos, nos quais há encontros face-a-face em conjunto com uma substancial proporção de atividades a distância (BOWMAN, 20|4).

\section{Considerações finais}

vertiginoso avanço do Covid-19 apresentou ao mundo uma situação inédita, com profundas implicações para diversas áreas. Segundo o retrato desenhado por Maria da Clória Gohn (2020), a pandemia desnudou desigualdades, mostrou a fragilidade de estruturas médicas e sanitárias, deixando evidente o fracasso das políticas econômicas existentes. A autora também destaca o papel das novas tecnologias, que em tempos de coronavírus funcionaram como único meio de ligação das residências em isolamento e o mundo exterior, e com as quais "cada um faz de seu confinamento uma ficção, pois fala, vê, escreve e envia sinais para quem quiser" (COHN, M. G., 2020, p. 16). Portanto, as escolhas que os individuos fazem na internet determinam as aprendizagens e transformações que resultam desse período de confinamento, passando pela educação não formal e chegando às instituições formais de ensino.

Em tempos de coronavírus, a reconfiguração de processos educacionais em todos os níveis, do ensino básico ao superior, força a sociedade a participar de debates que nem sempre serão bem-vindos. A educação a distância passou de opção a obrigação, o que sem dúvidas irá revelar muitas ressalvas dos descontentes. Conforme alertado por Litto (2010), a EAD não é para todos, pois indivíduos "que não estejam prontos para estudar com bastante independência, autonomia e pró-atividade, que não estejam maduros o suficiente para ter bons hábitos de trabalho [...] dificilmente terão uma boa experiência" (LITTO, 2010 , p. 58). Também os indivíduos motivados e maduros poderão sofrer 
com entraves diversos, a exemplo de limitações com tecnologias, falta de equipamentos apropriados e dificuldades com as metodologias de ensino. Ignorando todas as nossas diferenças, a necessidade de distanciamento ou isolamento social coloca-nos em uma estrada sem retorno, acentuando a presença tecnológica na educação, certamente deixando marcas também para o pós-pandemia.

No campo da educação musical, o uso de recursos tecnológicos tem sido comum há décadas, facilitando a produção de partituras, gravações sonoras e trabalhos com conteúdos diversos (COHN, 2003). Por isso, não se pode considerar como novidade as ferramentas digitais para notação musical, treinamento auditivo, edição de áudio e demais tarefas relacionadas. No entanto, houve novidade em depender mais intensamente dessas ferramentas, não somente para a produção de materiais, mas também para transpor a separação geográfica que abruptamente surgiu entre professores e alunos. Ademais, emergiu uma completa dependência de ambientes virtuais de aprendizagem e dos softwares de videoconferência, além de aplicativos de mensagens e redes sociais, para estabelecer comunicações nos processos educacionais.

A excepcionalidade da pandemia criou uma situação emergencial, demandando respostas imediatas em alguns casos, e muitas vezes planejamentos de ações sem contar com muitos recursos. Novos paradigmas despontaram, com a reformulação de experiências anteriores na $E A D$, inseridas na conjuntura gerada pelo Covid-19. Melhorias nas condições de trabalho dos professores se tornam necessárias e são possíveis somente com pesquisas sobre metodologias de ensino e investimentos em equipamentos, ainda que esses tenham que ser feitos de forma pessoal. Nesse sentido, tendo as disciplinas de bateria da UFSCar como pano de fundo, este artigo apresentou uma breve reflexão com ideias para viabilizar aulas on-line e lapidar a transmissão de conteúdos. Os mesmos princípios poderão servir a aulas de outros instrumentos musicais, considerando suas especificidades e o contexto em que estão inseridas.

\section{Referências}

ARCHIBALD, Mandy M. et al. "Using Zoom Videoconferencing for Qualitative Data Collection: Perceptions and Experiences of Researchers and Participants". International Journal of Qualitative Methods, v. 18, pp. 1-8, jan. 2019. 
BORCES, Daniela. Ensino a distância na quarentena esbarra na realidade de alunos e professores da rede pública. BBC News Brasil, Il maio 2020. Disponível em: https://www.bbc.com/portuguese/brasil-52568678. Acesso em: 28 maio 2020.

BOWMAN, Judith. Online Learning in Music. Foundations, Frameworks, and Practices. New York: Oxford University Press, 2014.

BRASIL. Portaria 2.117, de 6 de dezembro de 2019. Dispõe sobre a oferta de carga horária na modalidade de Ensino a Distância (EaD) em cursos de graduação presenciais ofertados por Instituições de Educação Superior (IES) pertencentes ao Sistema Federal de Ensino. Diário Oficial da União, Brasilia, DF, 6 dez. 2019. Disponivel em: http://www.in.gov.br/en/web/dou/-/portaria-n-2.117-de-6-de-dezembro-de-2019-232670913. Acesso em: 4 jun. 2020.

BRETT, Thomas. "Virtual drumming: a history of electronic percussion”. In Hartenberger, R. (ed.). The Cambridge Companion to Percussion. Cambridge: Cambridge University Press, 2016 . pp. 82-94

DAVIES, Gil. The effectiveness of LOLA (LOw LAtency) audiovisual streaming technology for distributed music practice. 2015. Masters research diss., Edinburgh Napier University, Edinburgh.

DEAN, Matt. The drum: a history. Plymouth: Scarecrow Press, 2012.

$\mathrm{COHN}$, Daniel M. Autoaprendizagem musical: alternativas tecnológicas. São Paulo: Editora Annablume, 2003.

$\mathrm{COHN}$, Daniel M. Educação musical a distância: abordagens e experiências. São Paulo: Cortez Editora, 2011.

$\mathrm{COHN}$, Daniel M. "A Internet em desenvolvimento: vivências digitais e interações síncronas no ensino a distância de instrumentos musicais". Revista da ABEM, v. 21, n. 30, pp. 25-34, jan./jul. 2013.

$\mathrm{COHN}$, Daniel M. "Educação musical com as tecnologias da EaD". In: Silva, Helena. L. e José Antônio B. Zille, orgs. Música e educação. Barbacena: EdUEMG, 2015. pp. 157-169 
$\mathrm{COHN}$, Daniel M. "The drum kit beyond the anglosphere: the case of Brazil”. In: BRENNAN, Matt; PICNATO, Joseph; STADNICKI, Daniel (Eds.). Cambridge Companion to Drum Kit. Cambridge: Cambridge University Press, 2020 (no prelo).

$\mathrm{COHN}$, Maria da Clória. "Educação não-formal: direitos e aprendizagens dos cidadãos(ãs) em tempos do coronavírus". Revista Humanidades e Inovação, v. 7, n. 7, pp. 9-20, mar. 2020.

GRANZOTTO, Nicola; RUCCERI, Paolo. Drum sets characterization in acoustic laboratory. In: Second Vienna Talk, sept. 2010, Vienna. Proceedings... Vienna: University of Music and Performing Arts, 2010. pp. 73-76

LITTO, Fredric M. Aprendizagem a distância. São Paulo: Imprensa Oficial do Estado de São Paulo, 2010.

MOORE, Michael; KEARSLEY, Greg. Educação a distância. Uma visão integrada. Tradução: Roberto Calman. São Paulo: Thomson Learning, 2007.

PAIXÃO, André. "Só 6 das 69 universidades federais adotaram ensino a distância após paralisação por causa da Covid-19." Portal G1, Seção Educação, 14 maio 2020. Disponivel em: https://gl.globo. com/educacao/noticia/2020/05/1 4/so-6-das-69-universidades-federais-adotaram-ensino-a-distancia-apos-paralisacao-por-causa-dacovid- 19.ghtml. Acesso em: 28 maio 2020.

SHEPARD, Brian. "The global village gets a music school." Keynote address to the 55th College Music Society National Conference, San Diego, CA, 2012. Disponivel em: http://www.briankshepard.com/medial GlobalMusic.pdf. Acesso em: 5 jun. 2020.

TOSCANO, Jim. "Getting the most out of online lessons." Sabian Education Network: Resource Library. Documento PDF. 2020. Disponivel em: https://sabianed.com/pdf/ 1586530505 -getting-the-most-out-of-online-lessons-pdf.pdf. Acesso em: 5 jun. 2020. 


\section{Sobre o autor}

Daniel Gohn é professor do curso de Licenciatura em Educação Musical da Universidade Federal de São Carlos (UFSCar). Mestre e Doutor pela Escola de Comunicações e Artes da Universidade de São Paulo (ECA/USP) e Bacharel em Música Popular pela Universidade Estadual de Campinas (Unicamp), é autor de "No Mundo da Bateria: conceitos, ideias e composições", em parceria com Jayme Pladevall (Editora Som, 2019), "Caderno de Percussão Yamaha" (Ricordi, 2014), "Educação Musical a Distância: Abordagens e Experiências" (Cortez, 201 1), "Tecnologias Digitais para Educação Musical" (EdUFSCar, 20 I0) e "Autoaprendizagem Musical: Alternativas Tecnológicas" (Annablume, 2003). Seus principais interesses de pesquisa incluem o uso de tecnologias na educação musical e processos de ensino e aprendizagem de instrumentos de percussão.

Recebido em 05/06/2020

Aprovado em 16/09/2020 